\title{
Dominant Language Acquisition in destination countries: Structure, Agency and Reflexivity
}

\section{Gina Netto, Maria Hudson, Nicolina Kamenou-Aigbekaen and Filip Sosenko}

Abstract: This article advances understanding of the structural and agentic factors which influence how migrants in low-paid work reflexively acquire the dominant language of destination countries. Bourdieu's theories on the symbolic power of language and habitus, and theories of reflexivity by Archer and others underpin our analysis of how migrants acquire English in the UK. Analysis of data generated from in-depth qualitative interviews with thirty-one migrants from EU and non-EU countries in low-paid work reveals that the agency of migrants in increasing proficiency in the language is shaped by access to resources, conscious and unconscious reflexive processes, aspects of embodiment and perceptions of identity by the self and others. We argue that closer attention to the social, political and economic context in which migrants acquire the dominant language of destination countries is needed, as well as greater awareness of the multi-dimensional nature of reflexivity and the constraints on agency.

\section{Introduction}

While the 'super-diversity' of migrants and drivers, patterns and itineraries of migration have contributed to increases in the number of languages spoken in destination countries (Vertovec, 2007), the privileged position of the dominant language is well-established (Bourdieu, 1981; Blommaert and Rampton, 2011). The view that the dominant language is a source and medium of symbolic power (Bourdieu, 1981) which privileges some groups and excludes others, as well as a vehicle of communication, has been supported through several quantitative studies (Avsar, 2016; Chiswick and Miller, 2003; Dustmann and Fabbri, 2003). These studies have established clear links between increased proficiency in the majority language of the destination country and labour market position. This view has also been supported by a growing number of qualitative studies which have shown that competence in the dominant language influences migrants' access to social networks and job opportunities (Morosanu, 2016;Ryan, 2016; Thusen, 2017). The role of language in communicating migrants' identity has also been firmly established (Temple, 2010; Johansson and Śliwa, 2014). For instance, Johansson and Śliwa (2014) have highlighted that language not only plays an important role in differentiating between individuals, socially and organisationally, but also intertwines with other processes of social positioning, such as gender and ethnicity.

The prominent role that 'standard varieties' of the dominant language enjoy - that is, the varieties used by the government, the educational system and in international communication - has also been revealed (Creese, 2010; Madibbo, 2016). Acquiring these forms of the language pose a challenge for migrants from post-colonial contexts who are attempting to assert their linguistic competence in the destination country. Although they may have high levels of proficiency in the dominant language, they may not be familiar with standard varieties used in the country.

Understanding the nature of reflexivity among migrants who are acquiring the dominant language is important because it increases understanding of the factors which influence their decision-making processes, and their agency within the structural contexts in which they find themselves. While it has been acknowledged that reflexivity is pervasive in all linguistic practice (Blommaert and Rampton, 2011), the process through which migrants reflect on the complex social processes which accompany the acquisition of (standard varieties of) the majority language remains under-theorised and under-researched (Temple, 2010). This study aims to advance understanding of the factors which influence migrants' reflexivity in 
acquiring the language of the destination country, the nature of reflexivity in this area and the scope for agency in the process. It focuses on migrants' acquisition of English in the UK.

Current understandings of linguistic reflexivity are based on the view that individuals reflect on their own and others' communication, assessing the extent to which this matches established standards within specific geographical and historical contexts (Bourdieu, 1981; Bloomaert and Rampton, 2011). Our conceptual framework is informed by theories which recognise the conscious processes of reflexivity as well as the role of unconscious processes. We apply Archer's work on reflexivity $(2003,2007,2012)$ which emphasises conscious, rational processes to a new area, that is, migrants' acquisition of the dominant language of destination countries. In doing so, we employ her methodological toolkit for classifying 'internal conversations' to reflexivity in relation to language acquisition. We also build on the work of Bourdieu (1981) in engaging with the symbolic power of language as well as habitual, unconscious processes relating to its use. Additionally, our study engages with research which has revealed the role of language in forming and expressing perceptions of identity (Temple, 2010; Johansson and Śliwa, 2014) and a growing body of work on the role of emotions in acquiring a destination country language (Hinds et al, 2014; Tenzer and Pudelko, 2015). We argue that this approach provides a more complete picture of the complex process through which migrants acquire the dominant language in their new environment than theories which focus solely on rational processes or habitual dispositions.

Significantly, unlike other recent studies in migration which have tended to concentrate on groups of migrants of a single nationality (Temple, 2010;Ryan 2016, Morosanu, 2016), we draw on empirical research which comprises a mix of EU and non-EU migrants. This enables us to examine processes of linguistic reflexivity across individuals of diverse nationalities, possessing varying levels of proficiency in English on arrival. The rationale for focusing on low-paid migrants is three-fold. Firstly, migrants are disproportionately represented in such work in both North America and Western Europe (Alba and Foner, 2015; European Commission, 2014). Secondly, migrants working in low-paid jobs are less likely to be proficient in the majority language and more likely to invest in learning the language in order to progress to better paid work. Thirdly, the relationship between low-paid work and in-work poverty is well-established (Bertrand et al, 2012), strengthening the case for deepening understanding of how migrants attempt to progress occupationally.

In the remainder of the paper, we develop our understanding of the structural context within which migrants acquire the dominant language and the role of reflexivity in underpinning agency. We next discuss the empirical research which this article draws on and map key aspects of linguistic reflexivity through which migrants acquire and use the dominant language as they attempt to progress from low-paid work. We then discuss the theoretical and empirical contribution of the study in advancing understanding of structural factors, such as limited resources, time and the lack of acceptability of non-standard varieties of English used by some migrants in the UK, which constrain their agency in acquiring the language. Finally, we highlight the multi-dimensional nature of reflexivity that the study has revealed and its methodological contribution.

\section{The role of structure, identity and agency in dominant language acquisition}

Structural factors play a key role in current understandings of linguistic reflexivity (Bourdieu, 1981; Bloomaert and Rampton, 2011) since individuals' assessment of their own and others' communication reflects issues related to identity, including values and inequalities in the positioning of social groups and access to communicative resources (Temple, 2010).

Attesting to the power dynamics which influence the assessment of linguistic competence and the role of identity in the process, Brubaker (2015) has highlighted the role that withinlanguage inequalities can play in both expressing extra-linguistic inequalities or structural factors and reproducing them. Within-language inequalities include accent, pronunciation, variety of language and linguistic repertoires, ranging from the formal to the informal. Extra- 
linguistic inequalities may be manifested through ethnicity, nationality, migrant status or other aspects of identity (Brubaker, 2015).

Chiswick and Miller's (2001) influential work identified three bundles of factors which are conducive to destination country language acquisition, namely, exposure, efficiency and incentives. Agentic factors which increase exposure to the language include participating in language classes, consuming host country media and using the language for social interaction, particularly with native speakers, although these may be influenced by structural factors, such as the cost of language classes. Efficiency in language learning is associated with higher levels of education, with more educated learners likely to become more proficient in the dominant language than less educated learners (see also Van Tubergen and Mentjox, 2014). Economic incentives for acquiring the language, such as achieving higher levels of employability or earnings, may be viewed as structural factors which incentivise agency in this area. Conversely, non-economic factors, such as intended length of stay in the country, which is likely to influence commitment to learning the language, may be viewed as agentic.

In addition to these structural and agentic factors, a growing body of research has begun to analyse the role of emotions in acquiring destination country languages. For instance, Temple's (2010) study of UK-based Polish migrants, demonstrated that acquiring a new language can be 'traumatic' since aspects of identity are deeply implicated in the use of language. Moving across languages raised fundamental issues related to the nature of lives the participants wanted to live and the people they wished to become. The painful emotions accompanying the learning of a new language, such as anxiety and fear of loss of face, have also been identified within organisational contexts, with impacts on individuals' and organisational performance (Hinds et al, 2014; Tenzer and Pudelko, 2015). However, little attention has been paid to the ways in which such emotions relate to linguistic reflexivity and agency in acquiring the dominant language.

Key research questions that relate to reflexivity are: How are inequalities in access to the resources required for dominant language acquisition mediated by the process? How do migrants' reflections of multiple aspects of their identity and the perceptions of others influence language learning? How are factors such as exposure and incentives for language acquisition mediated by rational and emotional processes? Adding a further layer of complexity, we now turn to consider the relative contribution of reflexivity and habitus in the efforts of migrants to acquire English.

\section{Language acquisition, habitus and reflexivity}

According to Chiswick and Miller (1995), while acquisition of language skills in one's native language appears almost effortless since it occurs naturally through formal and informal learning and social interactions, learning the dominant language of a destination country requires effort and determination. It is also important to consider the role of attachment to the native language in acquiring destination country languages. Bourdieu's habitus offers a useful conceptual tool for investigating this area.

For Bourdieu (1981:12), habitus denotes 'a set of dispositions which incline agents to act and react in certain ways.' Habitus is formed unconsciously in response to expectations of the structural contexts in which agents live. The concept thus presents a contrast to Archer's $(2003,2007)$ theorising of reflexivity which is viewed as being undertaken through largely rational 'internal conversations.' These inner dialogues enable individuals to engage and clarify their beliefs and ambitions, interpret and evaluate their circumstances and design projects based on their main concerns. Archer has argued that this internal conversation mediates the impact of structure on individuals' agency. Further, she has also developed a toolkit for investigating reflexivity (Archer, 2007) which classifies the rational processes involved and which we have employed in our empirical study, as discussed below. While Archer's work on reflexivity has been widely cited, it has received some criticism for its lack 
of attention to the ways in which individuals relate to each other and the role of feelings in the process (Burkitt, 2012). The lack of emphasis in her work to access to resources by under-privileged groups has also been identified as a shortcoming (Caetano, 2015; Mutch, 2004). Her lack of attention to habitual action in individual responses to structural factors has also been observed (Caetano, 2015; Gronow, 2008).

However, it is important to note that in her later work (2012: 47), Archer explicitly acknowledges the enduring influence of habit - defined as 'habitual, routinized or customary action' - in social theory. She questions whether 'habit' and 'reflexivity' have indeed 'stood in a zero-sum relationship over the last hundred years of theorizing' and argues that rather than overgeneralizing the importance of either habit (or habitus) or reflexivity, it is necessary to investigate the importance of both in relation to specific 'time, place and conditions' (Archer, 2012: 55). We follow this approach in assessing the relative contribution of conscious and unconscious processes in migrants' acquisition of the destination country language. Consistent with Archer's approach, we analyse structure and agency as distinct processes which operate on different timescales, with the former preceding the latter. Applied to our empirical study, this involves investigating the extent to which structural factors which have shaped beliefs and attitudes in the country of origin continue to influence reflexivity and agency in acquiring English in the destination country.

\section{Research Design}

The social science research methods adopted were motivated by an interest in migrant reflexivity and scope for agency in acquiring the dominant language of destination countries rather than, for instance, variations in the languages spoken by groups of migrants. Study of the latter may have necessitated the use of sociolinguistic methods to collect data on linguistic variables (Hazen, 2014). The study was carried out in the UK during 2012 to 2013 when austerity measures had been implemented to reduce the budget deficit arising from the 2008 financial crisis. The country provides a highly relevant structural context for the research since its immigration policy and political discourse has placed increased emphasis on the acquisition of English. Analysts have noted new forms of linguistic 'gate-keeping' for recent arrivals (Hogan-Brun et al, 2009; Yuval-Davies et al, 2005) which intersect with broader themes of nation-building, control (Bloch and Hirsch, 2016) and social cohesion (Yuval-Davies et al, 2005).

The migrant sample which this paper draws on was part of a wider funded project on the aspirations of low-paid workers in England and Scotland. Five large organisations (with more than 1,000 employees) were selected. We have focused on migrants employed in three areas in England and Scotland (see Table 1). Two of these areas are urban with longstanding sizeable ethnic minority populations, while the third, a semi-rural area has historically been predominantly White Scottish, until 2004 when there was a growth of migrant workers due to EU expansion. Participating organisations cooperated in publicising the research and identifying individuals who were willing to take part in interviews.

\section{Place Table 1 here}

Migrants are defined as individuals who were born abroad, whose formative experiences were gained outside the UK and who are ethnic minorities. The term 'low-paid workers' is used to refer to individuals earning less than $£ 25,000$ per annum (the median personal income in the UK during the fieldwork period) and whose household income is eligible for subsidy by in-work tax credits. 
The sample was diverse, allowing exploration of the influence of key factors relating to linguistic reflexivity and its interaction with aspects of identity, such as gender and nationality and the variables of exposure, efficiency and incentives, identified by Chiswick and Miller (2001). Comprising 21 women and 10 men, it was heterogeneous in terms of levels of education, skills, and country of origin, with ages ranging from 21 to 55 and UK residency extending from one year to 33 years. On arrival in the UK, interviewees' educational attainment varied from completion of primary school to postgraduate level, with six possessing a degree and eight having completed college level education. Approximately half (15) of the migrants originated from Central and Eastern Europe, while others came from the Republic of Ireland (1), Africa (8), Asia (5), the Middle East (1) and South America (1). The inclusion of migrants from non-EU countries allowed us to examine how visible markers of differentiation, such as skin colour, influence recognition of competence in the dominant language. Just over half (16) of participants were married, seven were cohabiting, four single, while the remainder were either divorced or separated. All the interviewees were on permanent employment contracts, including in administration, cleaning, catering and caring. Nine were working on a part-time basis. The majority (24) expressed a wish to progress to better paid jobs.

\section{Data collection and analysis}

Hour-long interviews were carried out in private rooms made available for the purpose. Knowledge of English prior to migration varied considerably. Despite this, few difficulties were experienced in carrying out the interviews since all research participants had already acquired a basic level of fluency. However, we acknowledge that migrants' developing fluency in the language as well as the choice of English in the interviews may have affected how some individuals presented themselves and their attitudes to acquiring the language (Temple, 2008).

Grounded data analysis, facilitated by NVivo, was undertaken by Netto, Hudson and Sosenko. Netto next traced the development of individuals' work histories within the context of their household circumstances to develop instrumental cases of all participants (Stake, 2000). Such biographical methods have been advocated for better understanding migrant life trajectories, including the role of structural features in conditioning actions and meaningmaking processes (Halfacree and Boyle, 1993). Netto then analysed the transcripts based on the methodological toolkit which Archer (2007: 91) had employed in her empirical investigation of internal conversations. This consisted of ten categories for classifying reflexivity: 'prioritising', 'planning', 'imagining' 'mulling over', 'budgeting', 'deciding', 'reliving', 'clarifying' 'rehearsing' and 'imaginary conversations.' Analysis revealed a close relationship between the data and the first eight of these categories; the last two categories were not exemplified in the data. These categories emphasised the rational element of linguistic reflexivity. Netto next identified three other broad categories of words or phrases. The first related to Bourdieu's (1981) concept of habitus in the form of beliefs or habitual action which impacted on migrants' efforts to acquire English. Habitus was operationalised as migrants' use of their native language due to either established dispositions related to the language or other patterns of customary behaviour which hindered exposure to and use of the destination country language. An example of the latter was the tendency for women to take on the primary responsibility of caring which hindered participation in language classes. It was harder to identify unconscious beliefs or actions where these were not explicitly articulated. The second category referred to emotions or feelings in relation to language use and learning (for example, 'scared' or 'really very tired'). The third consisted of phrases which were concerned with participants' perceptions, as well as that of others, of their identity (for example, 'ethnic minority' or 'foreigner') She then studied the relationship between the categories which Archer (2007: 91) used in investigating reflexivity and these three other groups of words or phrases. 
Our analysis of the factors which influence linguistic reflexivity at various stages of acquiring the destination country language is discussed under (a) early experiences of acquiring English in the UK; (b) increasing proficiency in English and (c) assessment of linguistic proficiency of fluent speakers of non-standard varieties of English. In order to preserve anonymity, details of the participants' workplaces are not provided.

\section{Early experiences of acquiring English in the UK}

Participants' varied considerably with respect to previous knowledge of English highlighting the significance of exposure to the language in the country of origin Since financial difficulties were among the main drivers of migration, the pressure to secure a job soon after arrival was a recurrent theme. Such priority-setting has been identified as a key feature of reflexivity (Archer, 2007: 91). This was common among individuals who were fluent in the language, such as Michael, as well as those with limited proficiency, such as Elena:

'I had to do anything to survive, and by then the only job I could get was the kitchen porter.' (Michael, college graduate from Ghana, assistant quality manager)

'When I am here, I was just working because I need money, money, money. Later I decide that maybe I want to learn English better.' (Elena, college graduate from Lithuania, supervisor)

Michael's narrative suggests a conflict between the structural constraint of making ends meet and the realisation that the job he has secured does not match his educational qualifications and proficiency in English. In contrast, Elena appeared to have more modest expectations although she too was a graduate. This can perhaps be attributed to her previous lack of exposure to the language and high awareness of its importance within the UK. Her narrative also reflects a process of 'deciding' (Archer, 2007: 91) to learn the language when the financial pressures had eased, which also reinforces the importance of 'budgeting' (Archer, 2007: 91). Participants' employment in such jobs appear to be rationally driven given the barriers to securing appropriate employment, although unconscious dispositions, for instance, appropriate roles for women and men, may also be at work.

Supporting previous research on opportunity structures (Kennedy, 2010), initial jobs were often found through intra-ethnic social networks. Some participants 'got by' with limited levels of fluency in English through seeking employment where the presence of other migrants made it possible to communicate in languages other than the dominant one. This may be viewed as both a conscious strategy to find employment wherever possible as well as an unconscious desire to speak the native language due to its familiarity and association with identity. For instance, fieldwork in a semi-rural site revealed several interviewees who had previously found employment in the same factory where they could converse with others from the same country or region in German, Polish or Russian. In this site, the small number of workplaces may have played an important role in facilitating migrant networks through languages other than English. However, they also indicate the potential for unconscious dispositions to speak in the native language to undermine rationally driven reflexive processes which favour increased exposure to English and its acquisition. These case studies highlight how opportunity structures within a specific geographical location interact with agency, language use, identity, habitus and the formation of social networks.

The attraction of working in an environment where it is possible to converse in a familiar language is reinforced through the feelings of fear and anxiety that some interviewees expressed when encountering structural contexts where communication in English was anticipated. The following quote from Olga, a Ukrainian university graduate, vividly illustrates this through her 'reliving' (Archer, 2007: 91) of her early experience: 
'When I came here, it was very difficult. I remember two months I spent at home. I didn't even go out to the shops. My mum, she was screaming, 'Please go to the shop...You have to talk to someone...' I was like scared."

Such narratives illustrate that although participants may be aware that increased exposure to the destination country language can facilitate its acquisition, they may be fearful of engaging in social interactions which require its use. The experiences of others who relived their early experiences served to highlight that in some structural contexts, the relational aspect of speaking in English could indeed be painful:

'Sometimes she (his line manager) was rude. She always blamed me if...something happened in the laundry, even though, you know is not your fault. Because some foreigners, just like me, I am a foreigner, they are not fluent in how to speak English.' (Joe, an electric technician from the Philippines, who had worked in a laundry on arrival to the UK).

Obviously, you can hear the accent and when people get drunk, they just, you know, it's like an everyday thing ... just because I'm female, I am from different country...The first year was really hard just because the English wasn't as good and I didn't know how to take the comments. So I was like, kind of run away crying, you know. Now, I'm like, 'You know I am better than you, say whatever you want to'. (Eva, college graduate from the Czech Republic, who worked at the bar of a hotel).

Such experiences reveal participants' perception that limited fluency in English can interact with migrant identity to contribute to discriminatory treatment in interactions with managers or service users and reinforce the symbolic power of the language in the UK. Both narratives extend Johansson and Śliwa's (2014) work in revealing that language may not only intertwine with aspects of identity such as migrant status, nationality and gender to differentiate between individuals but may be experienced as triggering abuse. Eva's case can be differentiated from Joe's who highlights only his 'foreigner' identity as contributing to his poor treatment. In contrast, Eva is aware that it is not only her accent, which signals her as a non-native, and identifies her as a target for harassment, but its intersection with her female identity. Both extracts reveal that migrating to the UK raised participants' awareness of aspects of their use of the language that they had not previously been conscious of (Bourdieu, 1981). Additionally, Eva's narrative signals that growing competence in the dominant language may lead to increased ability to cope with abuse, reinforcing the symbolic power of the language.

\section{Increasing proficiency in English}

Elements of cognitive linguistic reflexivity were apparent in interviewees' awareness that mastery of English was key to progression. The quotes below are typical in illustrating awareness of the benefits of prioritising (Archer, 2007: 91) the acquisition of English for career advancement while highlighting the challenges inherent in achieving this:

'If you want to find a better job, you have to speak English very well...and that is not easy for us.' (Brigita, college graduate from Lithuania, cleaner)

'First of all, I need to improve my English because it is quite difficult with writing also. And a lot of jobs here, it is reception or library clerks, so you need to write also.' (Gabriela, university graduate from Poland, cleaner)

Such narratives reveal participants' awareness that progression involves entering into new structural contexts with additional demands for communicating in English with colleagues, managers and service users. Even skilled participants who had previously learnt English in 
their country of origin experienced difficulties in transferring their linguistic capital to a new setting. Such was the case of Hannah, a former nurse from Hungary, who had moved to the UK four years prior to the interview and initially took up work in house-keeping. 'Mulling over' (Archer: 2007: 91) her experience, Hannah observed:

'I think that's kind of common, that foreign people start like a housekeeper, kind of cleaning work. I had an English education....but it didn't worth anything. So I had to start everything from the beginning.'

Hannah is aware that the process of acquiring English is embodied in her new identity as a migrant to the UK and that only a restricted range of varieties of English are acceptable in the country. Further, she positions her career trajectory as being typical of that of other migrants. Within the context of these conditions, her decision to take up a housekeeping role may be viewed as rationally motivated. However, it is also possible that unconscious dispositions related to, for example, appropriate employment for women, may have influenced her choice.

Formal instruction in the language was widely viewed as helpful, demonstrating cognitive elements of linguistic reflexivity. Below, Hannah recalls her decision-making process (Archer, 2007: 91):

'After one year, I realised that I need to move on. I wanted to get more. My English was still poor and I applied to the college to the English course.'

At the time of interview, Hannah had gained sufficient proficiency in English to have advanced to a waitressing position in the same hotel. Her progression to a better paid job, while still not commensurate with her qualifications, reveals that within some conditions, gaining recognised linguistic capital could result in promotion. However, as Hannah and others revealed, significant periods of time could elapse before participants achieved sufficient financial stability to attend classes, reinforcing Archer's (2003) view that structural factors precede agency. For some, this was due to the cost, while others had to sacrifice some working hours in order to attend. In households with children, combining work with parenting responsibilities was an additional challenge. This was the case with Ravi, a former social worker from India, who felt that his lack of fluency in English was a major barrier to progressing from his current role as a catering assistant. Below he explains how he and his wife share the care of their nine year-old daughter and how this constrains attending classes:

'I am working day duties and she is working the nights...there's no opportunities here because we both work, me and my wife daily. The cost of living is very high.'

Such accounts reinforce how limited financial capital restricts agency in acquiring the linguistic capital necessary for progression and contributes to prolonged periods of employment in low-paid work (Hudson et al, 2017).

Among participants who had enrolled in language courses, the physical fatigue associated with the manual nature of their jobs presented a formidable challenge. In Brigita's words:

'If you get up always at 5 o'clock and you are working all day. And if you have to go to college from 7 to $9 \mathrm{pm}$, then really, you feel very, very tired.'

Such narratives highlight the embodied aspects of language acquisition among migrant lowpaid workers which their counterparts in more skilled jobs may not experience and which hinders agency in acquiring the dominant language. Further, highlighting the gendered 
nature of the process, in some cases, the birth of a child and caring responsibilities, emerged as major obstacles to women's successful completion of courses. Below, two women explain why they either did not take up the offer of a language place at college or had to stop attending classes:

'The reason why I didn't go because I get pregnant. I get married, I get pregnant and unfortunately, now I have to say "no" to lots of things in my life.' (Olga)

'I did went to college $X$ for three years, I had to pay and study for three years, part time, not full time. Only once a week...I studied English as a foreign language....And when I have a baby, that's how I stopped.' (Mei Ling, from Vietnam, catering assistant)

These narratives, along with those of a number of other women who reported discontinuing their participation in language courses after childbirth, highlight the strong potential for unconscious dispositions in the form of gendered obligations relating to the habitual care of children to slow down the often conscious process of language-learning. These challenges are compounded by the lack of sufficient household resources available for childcare and class costs. At the macro-level, these structural constraints are reinforced by a lack of affordable childcare (Harding et al, 2017) and cuts to the provision of English as a Second Language (Bassel et al, 2017).

However, despite these challenges, migrants demonstrated agency in acquiring the language through other strategies, including reading, exposure to the media and socialising with other English speakers. Ali, who came from a farming background in Kurdistan, and was currently working as a domestic, communicated a conscious process of 'planning' how he would increase his proficiency in the language and 'imagining' (Archer, 2007: 91) new opportunities which he could take up:

'I speak Kurdish already, there is no point sitting with Kurdish people...better put the effort in there to learn the language....When I go home...I just watch Sky... and British TV. To learn the language, to learn the attitude, to learn the culture so if you encounter something you can be success.'

Similarly, Eva, who migrated from the Czech Republic soon after finishing college, recalled how she had developed fluency in the language through a 'planned' (Archer, 2007: 91) strategy she adopted in her role as a barista in a hotel:

'Rather than hide in the corner, I tried to socialise with people and learn the language.'

Both narratives illustrate the scope for individual agency in creating linguistic contexts which are conducive to increasing exposure to English. However, this was not the case for others. For instance, 'mulling over' (Archer, 2007: 91) her experience of acquiring English, Olga, who spoke Russian and Ukrainian at home reflected:

'I know I have to speak English 24 hours a day, I feel like that. Because some days I come into work and I can't speak at all, I don't know why, it is like something stuck. You know, because so many languages at home, like with my family, with my mum...so it is a bit difficult to change always.'

Olga's narrative clearly illustrates the tension she experiences between her awareness of the usefulness of speaking English throughout the day and the physical difficulty that she faces in doing so ('like something stuck'). Such insights extend Temple's work (2008) on the affective dimension of adopting the destination country language by highlighting individuals' 
awareness of the bodily impact of navigating multiple linguistic environments and may reflect unconscious dispositions towards speaking the native language

Reinforcing the link between English and bodily sensations, Elena, a former factory worker from Lithuania who came to the UK nine years prior to the interview and who was working as a supervisor also revealed awareness of the feelings evoked through contact with others who were competent in the dominant language. Highlighting the significance of this dimension of reflexivity, she had turned down an offer of promotion despite her apparent ease in communicating in English, because she felt that she had still not acquired a sufficient level of proficiency:

'A few times my boss asked me to become like a Contract manager or Area Supervisor. I know my job..., but the problem is the language. In future, ..., maybe I try to learn English better, because to be manager, your English has to be $80 \%$. And mine is about $50 \%$...To sit down as business people, it is not enough... Sometimes, maybe we worry too much about that but it's not easy when you can't understand properly. Sometimes you feel not very well here inside.'

Despite the confidence of her line manager in the adequacy of her English and readiness for progression, Elena's own view was that she had yet to acquire the more formal style that would be expected in the new role. Further, her narrative reveals that the affective dimension of unease (feeling 'not very well...inside') arises in situational contexts where competence may be found to be lacking by individuals who are in more senior roles. This is consistent with studies which have found that language-induced emotions are linked to fear of negative appraisals of performance (Tenzer and Pudelko, 2015). Such findings extend Temple's (2010) study in revealing that migrants are aware that words do not simply contain meanings and evoke bodily experiences but also signal different varieties of the language that they are still in the process of acquiring.

\section{Assessment of linguistic proficiency by others}

In contrast to individuals who were attempting to improve their competence in English, those who were already proficient highlighted a lack of acceptance of non-standard varieties among colleagues of the language. Supporting Creese (2010) and Brubaker (2015), 'withinlanguage' inequalities identified included disapproval of non-standard accents and correction of punctuation:

'There was a time we had an agency staff member: her accent was a bit different and then somebody asked, 'why did we use that agency staff again?'...So I am thinking we all have different accents, so I found that a bit offensive ... The question is... how many people talk behind your back and say, 'Oh well, I never understood her'... it makes you think... how much are they talking about me?' (Mary, UK-qualified post graduate from Kenya)

'When you pronounce a word, they like to correct you as if their own pronunciation.... is the best ... They want to say they're not racist, but I think racism is always there in the back of every person's mind, no matter what, you know.... when they start correcting you with your pronunciation... you will just stop and say..., 'Okay, I can't be bothered with these people.' That's how you feel, and just you know, let them have fun.' (emphasis added) (Sarah, UK-qualified postgraduate from Swaziland)

The extracts reveal that although both participants possessed UK-based postgraduate qualifications, their proficiency in English might not be recognised by others due to their accents or differences in pronunciation. The extracts also reinforce the persistence of habitual dispositions related to the variety of language spoken by those whose proficiency 
derives from the legacy of British imperialism. Additionally, extending Creese (2010) and Brubaker (2015), these narratives provide evidence of how participants experience nonacceptance of their language use: as either 'offensive' or as evoking resignation due to the inability to challenge such practices. Both participants were among a small number of migrants from sub-Saharaan Africa in their organisations. It is possible that 'place' may play a role in the levels of acceptance of non-standard varieties of the language, with greater levels of acceptance occurring in structural contexts with a longer history of accommodating migrants. It is possible that should such workplaces become more ethnically diverse over time, there may be greater levels of acceptance of non-standard varieties of destination country languages.

\section{Discussion}

The study has increased understanding of the structural factors which influence language acquisition among low-paid migrant workers through the lens of reflexivity. These include previous exposure to the language, financial resources, participation in language classes, awarenessof lack of fluency in the language and under-recognition of proficiency in nonstandard varieties of the language. Among those who had previously not learnt English, the scarcity of language classes in the UK (Bassel et al, 2017) combines with migrants' low income, and in some cases, caring responsibilities, to present formidable challenges to increasing exposure to the language in this way. Other difficulties include their vulnerability to abuse and hostility in work and other settings due to the low tolerance of some native speakers to early levels of proficiency in the language. Those who have previously learnt English in their countries of origin face fewer challenges in understanding and using the language than those who had not. However, they too face obstacles in gaining recognition in the UK of their English competence due to negative attitudes relating to the use of nonstandard varieties of the language. These findings support Brubaker's (2015) work on the potential for within-language inequalities to reflect and reproduce extra-linguistic inequalities based on migrant status, ethnicity and nationality. It illustrates that migrants' efforts to integrate within workplaces can be facilitated by greater acceptance among the local population of varying levels of proficiency of English and the use of different accents and pronunciation. The study thus reinforces and extends research which has established that integration is a two-way process which requires 'a harmonious, equal and welcoming society' (Castles et al, 2002: 31). This presents a contrast to the language-based exclusionary processes that new arrivals are subjected to in the UK (Hogan-Brun et al, 2009; Yuval-Davies et al, 2005).

The study has also revealed that linguistic reflexivity is neither entirely rational as might be expected by Archer $(2003,2007)$ nor wholly driven by habitual dispositions, as might be expected by Bourdieu (1981). Rather, it is a highly complex process, through which migrants' reflexive processes are mediated not only by the multiple conscious processes of 'prioritising', 'planning', 'mulling over', 'deciding', 'reliving' 'imagining', 'clarifying' and 'budgeting' (Archer, 2007) but also by unconscious beliefs and dispositions that may be linked to habitus (Bourdieu, 1981), such as attachment to the native language. Further, our study shows that emotions, such as fear and anxiety, and bodily experiences, such as fatigue and unease, also influence language acquisition. We have also demonstrated participants' awareness that their language use communicates or reinforces their migrant identity and in some cases at least, adversely shapes their treatment within the workplace.

This enriched understanding of linguistic reflexivity is significant because it highlights that exposure, efficiency and incentives, which Chiswick and Miller (2001) have identified in their influential study as crucial factors which facilitate language acquisition in the destination country, are mediated by conscious and unconscious processes, access to resources, emotional responses and bodily experiences within specific 'times, place and conditions' (Archer, 2012: 55). This more complex conceptualisation of the processes of destination 
country language acquisition paves the way for further empirical research into the ways in which migrants from a variety of language groups reflexively acquire the dominant language in other destination countries. Such work can also contribute to better understanding of the structural factors which facilitate or hinder language acquisition and the scope for agency among different groups of migrants, including along the dimensions of nationality, gender, age, income and social support. The study thus represents a conceptual bridge between research which has focused on the factors which facilitate destination country language acquisition among migrants (Chiswick and Miller, 2001) and future research into the interaction of structure, agency and the multi-dimensional aspects of linguistic reflexivity.

Methodologically, the diversity of our sample which included migrants from EU and non-EU countries, has provided us with the opportunity to investigate groups which are rarely studied together. These included participants who had previously learnt English as well as others who had not. This has allowed us to reveal the specific challenges that different groups of migrants encounter at various stages of acquiring (standard varieties of) the language and gaining recognition of their linguistic competence. The study has also developed an analytical process for interrogating linguistic reflexivity derived from the combined use of the coding of recurrent themes, the treatment of participants' biographies as representations of conscious and unconscious dispositions to language learning, the use of Archer's (2007) toolkit for investigating rational aspects of linguistic reflexivity and the development of categories to capture unconscious processes, emotional responses and embodied factors.

\section{Conclusion}

The study has increased knowledge of the structural factors which shape the conscious and unconscious reflexive process through which migrants acquire the dominant language of destination countries, a process which involves rational elements as well as emotional responses. By drawing on theories which emphasise the rational aspects of reflexivity as well as those which emphasise its habitual aspects, and recognising the role of emotions in the process, it provides a fuller understanding of the scope for agency among migrants in acquiring the language, and especially, the constraints. Such knowledge increases appreciation of the challenges that migrants encounter in acquiring the language and the need for access to a variety of resources, including sufficient levels of income, social support from managers and colleagues, time to invest in language learning and psychological resources such as confidence in using the language, all of which mediate exposure to the language and incentivise its use. Understanding of the challenges which migrants in lowpaid work face also helps to demonstrate the need for more conducive environments for acquiring such languages in the form of greater levels of acceptance of varying levels of proficiency and the use of non-standard varieties in the workplace and beyond.

\section{References}

Alba, R and Foner, N (2015) Strangers no more: immigration and the challenges of integration in North America and Western Europe. Princeton and Oxford: Princeton University Press

Archer MS (2003) Structure, agency and the internal conversation. Cambridge: Cambridge University Press

Archer MS (2007) Making our way through the world. Cambridge: Cambridge University Press.

Archer MS (2012) The reflexive imperative in late modernity. Cambridge: Cambridge University Press. 
Avsar RB (2016) Cultural integration and occupational achievement among Mexican immigrants along the US-Mexico Border. Economics and Sociology 9 (1): 129 - 138

Bassel L. Monforte P, Bartram D, Khan K Miszta B (2017) The UK Citizenship Test Process: Exploring Migrants' Experiences Executive Summary. Date accessed 5th of February 2017

Bertrand M, Briaan, N and Whelan C (2012) Low pay, in-work poverty and economic vulnerability: a comparative analysis using EU-SILC. Manchester School 80 (1): 99 - 116

Bloch A and Hirsch S (2016) Second generation' refugees and multilingualism: identity, race and language transmission. Ethnic and Racial Studies 40 (14): 2444 - 2462

Blommaert J and Rampton B (2011) Language and superdiversity. Diversities 13 (2): 1 - 20.

Bourdieu P (1981) Language and symbolic power. Cambridge: Polity Press

Brubaker R (2015) Linguistic and religious pluralism: between difference and inequality. Journal of Ethnic and Migration Studies 41 (1): 3 - 32

Burkitt I (2012) Emotional reflexivity: feeling, emotion and imagination in reflexive dialogues. Sociology 46(3): $458-472$

Caetano A (2015) Defining personal reflexivity: a critical reading of Archer's approach. European Journal of Social Theory Vol 18 (1) $60-75$

Castles, S, Korac, M, Vasta, E and Vertovec, S (2002) Integration: mapping the field London: Home Office

Chiswick, B. R., \& Miller, P. W. (1995). The endogeneity between language and earnings: International analyses. Journal of Labor Economics, 13, 246-288.

Chiswick B.R. and Miller P.W. (2001) A model of destination-language proficiency acquisition: application to male immigrants in Canada. Demography 38 (3): 391 - 409

Chiswick B.R. and Miller P.W. (2003) The complementarity of language and other human capital: immigrant earnings in Canada. Economics of Education Review 22: 469-480.

Creese G (2010) Erasing English language competency: African migrants in Vancouver, Canada. International Migration and Integration 11: 295 -313

Dustmann C and Fabbri F (2003) Language proficiency and labour market performance of immigrants in the UK. The Economic Journal 113: 695 - 717

European Commission (2014) Employment and Social Developments in Europe 2015, http://ec. europa.eu/social/main.jsp?catld=738\&langld=en\&publd=7684\&furtherPubs=yes [accessed 27.05.2017].

Gronow A (2008) The over-or the undersocialised conception of man? Practice theory and the problem of intersubjectivity. Sociology 42 (2): 243 - 259

Harding C, Wheaton B and Butler A (2017) Childcare survey 2017 Family and Childcare Trust. https://ac-els-cdn-com.ezproxy1.hw.ac.uk/S0140673617330076/1-s2.0-

S0140673617330076-main.pdf? tid=spdf-024dd5d9-24ef-4e3c-81dc22c51a2b773b\&acdnat=1519724299 41e340db21d1128dd2e259840f2b1931

Date accessed $27^{\text {th }}$ February 2017 
Hazen, K (2014) 'A historical assessment of research questions in sociolinguistics' In Holmes, J and Hazen, K (2013) Research methods in sociolinguistics: a practical guide. Sussex: Wiley Blackwell

Hinds, PJ, Neeley, CD and Cramton, CD (2014) Language as a lightning rod: power contests, emotion regulation and subgroup dynamics in global teams Journal of International Business Studies 45(5) 536 - 561

Halfacree KH and Boyle PJ (1993) The challenge facing migration research: the case for a biographical approach. Progress in Human Geography 17(3): 333-48

Hogan-Brun G, Mar-Molilnero, C and Stevenson, P (2009) Discourses on language and integration: critical perspectives on language testing regimes in Europe. Vol 33 Amsterdam: John Benjamins Publishing International Migration and Integration 11: 295 - 313

Hudson M, Netto G, Noon, M, Sosenko, F, de Lima, P, and Kamenou-Aigbekaen N (2017) 'Ethnicity and low wage traps: favouritism, homosocial reproduction and economic marginalization' Work, employment and society 31(6) 992-1009

Johansson M and Śliwa M (2014) 'It is English and there is no alternative': intersectionality, language and social/organisational differentiation of Polish migrants in the UK. Gender, Work and Organisation 23 (3): 296 - 309

Kennedy P (2010) Mobility, flexible lifestyles and cosmopolitanism: EU postgraduates in Manchester. Journal of Ethnic and Migration Studies, 36 (3) 465 - 482

Maddibo A (2016) The way forward: African francophone immigrants negotiate their multiple minority identities. International Migration and Integration 17: 853 - 866

Morosanu L (2016) Professional bridges: migrants' ties with natives and occupational advancement. Sociology 50 (2): 349 - 65

Mutch A (2004) Constraints on the internal conversation: Margaret Archer and the structural shaping of thought. Journal for the theory of social behaviour 34 (4) $429-445$

Ryan L (2016) Looking for weak ties: using a mixed method approach to capture elusive connections. The Sociological Review: 951 - 969

Stake RE. (2000). Case studies. In Denzin, NK \& Lincoln, YS (Eds.), Handbook of qualitative research (pp.435-453). Thousand Oaks: Sage.

Temple B (2008) Narrative analysis of written texts: reflexivity in cross language research. Qualitative Research Vol 8 (3): 355 - 365

Temple B (2010). Feeling special: language in the lives of Polish people. The Sociological Review 58 (2): $286-304$

Tenzer, $\mathrm{H}$ and Pudelko, M (2015) 'Leading across language barriers: managing languageinduced emotions in multinational teams' The Leadership Quarterly 26(4): 606 - 625

Thusen $\mathrm{F}$ (2017) Linguistic barriers and bridges: constructing social capital in ethnically diverse low skill workplaces. Work, Employment and Society 31 (6) 937 - 953 
Van Tubergen F and Mentjox T (2014) Minority language proficiency of adolescent immigrant children in England, Germany, the Netherlands, and Sweden. Ko"Iner Zeitschrift fu"r Soziologie und Sozialpsychologie 66(1): 241-262.

Vertovec S (2007) Towards post-multiculturalism? Changing communities, contexts and conditions of diversity. International Social Science Journal 199: 83 - 95

Yuval-Davies N, Anthias F and Kofman E (2005) Secure borders and safe haven and the gendered politics of belonging: Beyond social cohesion Ethnic and Racial Studies 28 (3): 513-535 
Table 1: Participating organisations

\begin{tabular}{|c|c|c|c|}
\hline $\begin{array}{l}\text { Employer } \\
\text { name }\end{array}$ & Sector & Type of organisation and location & Area \\
\hline FacilitiesCo1 & Private & $\begin{array}{l}\text { Global facilities management company in an } \\
\text { urban area In England }\end{array}$ & 1 \\
\hline Housing & $\begin{array}{l}\text { Social } \\
\text { enterprise }\end{array}$ & Housing association in an urban area in Scotland & 2 \\
\hline Hotel & Private & International hotel in an urban area in Scotland & 2 \\
\hline $\begin{array}{l}\text { Health } \\
\text { service }\end{array}$ & Public & Health provider in a semi-rural area in Scotland & 3 \\
\hline FacilitiesCo2 & Private & $\begin{array}{l}\text { Large UK company, which operates in a semi- } \\
\text { rural area in Scotland }\end{array}$ & 3 \\
\hline
\end{tabular}

